\title{
Spatio-temporal changes in precipitation, temperature and their possibly changing relationship: a case study in the Wei River Basin, China
}

\author{
Shengzhi Huang, ${ }^{\text {a* }}$ Qiang Huang, ${ }^{\mathrm{a}}$ Hongbo Zhang, ${ }^{\mathrm{b}}$ Yutong Chen ${ }^{\mathrm{a}}$ and Guoyong Leng ${ }^{\mathrm{c}}$ \\ ${ }^{a}$ State Key Laboratory Base of Eco-Hydraulic Engineering in Arid Area, Xi' an University of Technology, China \\ ${ }^{\mathrm{b}}$ School of Environmental Science and Engineering, Chang'an University, Xi'an, China \\ ${ }^{c}$ Institute of Geographic Sciences and Natural Resources Research, Chinese Academy of Sciences, Beijing, China
}

\begin{abstract}
With the purpose of further understanding the spatio-temporal changes in precipitation, temperature and their possibly changing relationship in the Wei River Basin (WRB), a typical arid and semi-arid region in China, the modified Mann-Kendall (MMK) test method was used to capture their trends at monthly and annual time scales, and the $K$-means cluster analysis method was applied to divide the whole basin into three homogeneous sub-regions. Furthermore, a copulas-based method was introduced in this study to identify possible inflection points of the relationship between precipitation and temperature in the WRB. Results indicate that: (1) spatially, both annual average precipitation and temperature decreased from southeast to northwest; temporally, for most months, a decreasing trend was found for precipitation while the air temperature in most months has a significantly increasing trend at 99\% confidence level at monthly and annual time scales in the WRB; (2) climate warming has less effect on the precipitation structure than that on the precipitation magnitude in the WRB; and (3) overall, the relationship between precipitation and temperature in the whole WRB has no significant inflection point, implying a relatively stable relationship between precipitation and temperature changes. This study provides a new idea and quantitative measure for the identification of inflection points of the relationship between precipitation and temperature.
\end{abstract}

KEY WORDS precipitation and temperature; inflection point; copula; Bayesian copula selection method; modified Mann-Kendall test method; Wei River Basin

Received 15 April 2015; Revised 18 May 2015; Accepted 19 May 2015

\section{Introduction}

It is a common knowledge that the global climate has witnessed notable changes during the recent 100 years, which is mainly characterized by global climate warming (Wang et al., 2013a). The global average annual temperature has increased by $0.74^{\circ} \mathrm{C}$ within the past 100 years (Intergovernmental Panel on Climate Change, 2007). Climate change has exerted so strong impacts on society and environment like water availability, food security and health that they are becoming a major issue worldwide and has been investigated by many researchers (Easterling et al., 1997; Allen and Ingram, 2002; Alexander et al., 2006; Lima et al., 2013; Józsa et al., 2014).

Precipitation and surface air temperature, as the most important climate variables, can indicate the global climate change to a great extent (Alexander et al., 2006; Boccolari and Malmusi, 2013). Hence, their spatiotemporal changes were broadly studied in order to reveal regional response of hydrology to the global

\footnotetext{
* Correspondence to: S. Huang, State Key Laboratory Base of Eco-Hydraulic Engineering in Arid Area, Xi'an University of Technology, No. 5 South Jinhua Road, Xi'an 710048, China. E-mail: huangshengzhi7788@126.com
}

climate change (e.g. Wang et al., 2012; Boccolari and Malmusi, 2013; Wang et al., 2013b; Madanian et al., 2014). Boccolari and Malmusi (2013) investigated the changes in temperature and precipitation extremes observed in Modena, Italy, and found that the minimum temperature had a non-significant positive trend of $+0.1^{\circ} \mathrm{C} \mathrm{decade}^{-1}$ in $1861-2010$, and the value increased to $0.9^{\circ} \mathrm{C} \mathrm{decade}^{-1}$ during $1981-2010$, while precipitation was decreasing with a speed of $-6.3 \mathrm{~mm} \mathrm{decade}^{-1}$ during 1861-2010. Wang et al. (2013a) analysed the changes in extreme events of temperature and precipitation over Xinjiang, northwest China, during 1960-2009, and found that most precipitation indices showed an increasing trend in northern Xinjiang and exhibited a decreasing trend in southern Xinjiang. Wang et al. (2012) studied the trends of temperature and precipitation in the Loess Plateau Region of China during 1961-2010, and concluded that the region-averaged annual average temperature had significantly increased over the last 50 years $\left(1.91^{\circ} \mathrm{C}(50 \text { year })^{-1}\right)$, while the region-averaged annual precipitation exhibited a non-significant negative trend $\left(-29.11 \mathrm{~mm}(50 \text { year })^{-1}\right)$. All the above-mentioned studies suggested that the variations of precipitation and temperature significantly vary both in space and time (Mann et al., 2000). 
As known, precipitation is closely associated with temperature (Du et al., 2013). Therefore, precipitation will inevitably be affected under the background of climate change, which is primarily characterized by global warming. The global warming is expected to accelerate the hydrologic cycle (Ziegler et al., 2003; Allan and Soden, 2008). Arnell (1999) pointed out that the hydrologic cycle would be intensified with the increasing evaporation and precipitation, ultimately triggering an unequal distribution of precipitation over the world. Therefore, the relationship between precipitation and temperature may change because of the changing global climate, and some inflection points may exist. However, to the best of our knowledge, there are no relevant researches concerning detecting inflection points of the relationship between precipitation and temperature. The change in precipitation is expected to trigger drought and flood. Thus, the identification of inflection points of the relationship between precipitation and temperature will help further understand precipitation mechanism under the context of climate change, which is important to agricultural production, relief of drought and flood as well as water resources planning and management. This is the major objective in this study. Based on what outlined above, a new method based on copula was employed in this study to detect the possible inflection points of the relationship between precipitation and air temperature, which has been applied in financial field (Ye and Miao, 2009). However, to the best of our knowledge, the application of this method in identifying inflection points of the relationship between precipitation and temperature has not been found.

Furthermore, the use of copulas is increasingly growing, and it is essential to find a simple and reliable method to select an appropriate copula family in fitting the joint distribution of precipitation and temperature (Huard et al., 2006). Although numerous researchers have applied copulas to investigate hydro-meteorological extremes (Kao and Govindaraju, 2010; Wang et al., 2010; Palynchuk and Guo, 2011), most of them adopted a likelihood method such as the Akaike Information Criteria to choose the appropriate copula (Huard et al., 2006). However, the existing methods have a lot of drawbacks and none is completely satisfactory because of their failure in comparing distributions without specifying an optimizing parameter set for each one of them (Huard et al., 2006). Recently, a Bayesian copula selection method proposed by Huard et al. (2006) has resolved this problem, which is prior on Kendall's $\tau$ rather than parameters. Therefore, the Bayesian copula selection method was utilized to select the appropriate copula in this study.

Although the variations of hydrologic cycle are primarily influenced by the adjustments of large-scale atmospheric circulation at various spatial and temporal scales, the local effect can also be impacted by local land surface conditions (Jordan et al., 2014; Ling et al., 2014; Ma et al., 2014). Therefore, various regions may have different hydrologic responses to the global climate change (Trenberth, 1999; Lima et al, 2013). The Wei
River Basin (WRB) is a typical arid and semi-arid region. Its precipitation and temperature have a significant variability and the local underlying surface is highly complex (Huang et al., 2014a). High-frequency natural hazards, such as drought and flood, debris flow, sand storm, and others have been increasingly reported. Therefore, it is of importance to investigate the hydrologic response to the global climate change, mainly represented by the variability of precipitation and temperature, which will help to reasonably adjust the local economic structure and efficiently utilize available water resources, thus relieving the impacts of climate change on local society and economy. Moreover, as most of the loess plateau is situated in this basin, which is a typical ecologically vulnerable area, studying the spatio-temporal changes in precipitation, temperature and their possible changing relationship will also be useful in improving local ecology and environment through further understanding of local precipitation mechanism under the background of global warming.

Therefore, the main objectives of this study are: (1) to investigate the spatio-temporal change characteristics of precipitation and temperature at monthly and annual scales in the WRB; (2) to analyse the response of precipitation in different sub-regions to the variations of air temperature in the WRB; (3) to identify possible inflection points of the relationship between precipitation and air temperature in the WRB. In addition, the rest of this article is organized as following: in the next section, the methods adopted in the article are introduced; the study area and data are presented in Section 3.; the results and discussion are shown in Section 4.; finally, the conclusions of this paper are described in Section 5.

\section{Study area and data}

\subsection{Introduction of the WRB}

The WRB, as shown in Figure 1, was selected in this research. The Wei River is the largest tributary of the Yellow River, which lies between $103.5^{\circ}-110.5^{\circ} \mathrm{E}$ and $33.5^{\circ}-37.5^{\circ} \mathrm{N}$, covering a total area of $1.35 \times 10^{5} \mathrm{~km}^{2}$ (Zhang et al., 2008). The basin is characterized by abundant precipitation and high temperature in summer, and by rare precipitation and low temperature in winter. The annual precipitation is nearly $559 \mathrm{~mm}$ (Zhang et al., 2008). The Guanzhong Plain which lies in the south of the basin is a critically important agricultural production region. The plain is located in the edge of the monsoon, which is sensitive to global climate change and the alternation of environmental elements. Thus, available water resources tend to be affected by the changing climate, which is harmful to local agricultural production and economic development. In view of the food security and sustainable development in the WRB, it is important to investigate the spatio-temporal changes in precipitation, temperature and their possibly changing relationship in this region. 


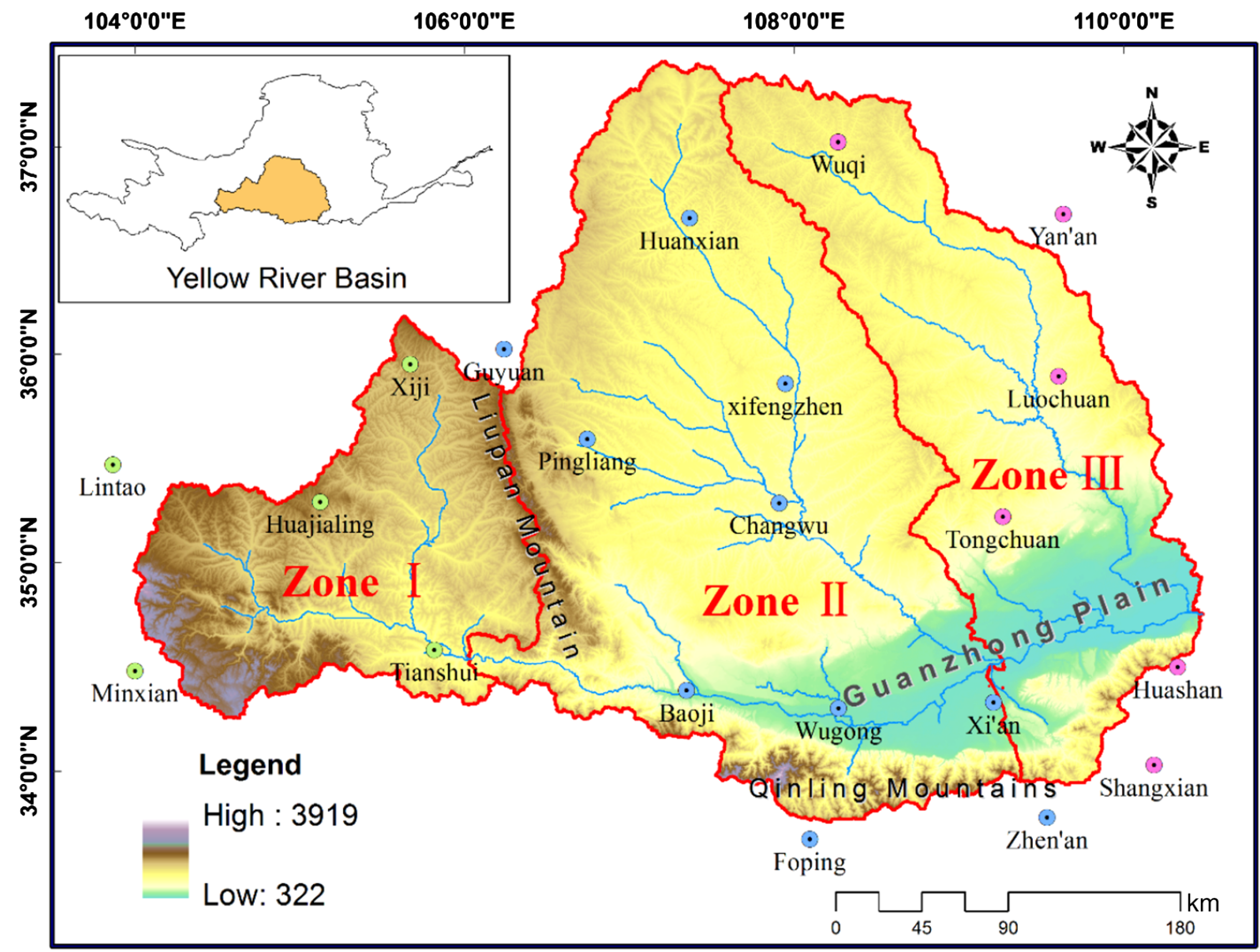

Figure 1. Study area and the relevant meteorological stations.

\subsection{Study data}

Daily precipitation and average air temperature data collected from 21 meteorological stations in the WRB were used in this study, whose locations are presented in Figure 1. The details of these stations are shown in Table 1. Each station has daily meteorological data covering from 1 January 1960 to 31 December 2008, which were acquired from the National Climate Center of the China Meteorological Administration. The data quality was strictly controlled during their release. Among the 21 stations, 2 stations have some missing values, but the portion of total lost data is less than $0.01 \%$. The missing data were reconstructed by calculating the average value of their neighbouring stations. In addition, the double-mass curve method was used to check the consistency of the data, and the results indicate that all the daily meteorological data adopted in the study are consistent.

\section{Methodology}

\subsection{The modified Mann-Kendall trend test}

The modified Mann-Kendall (MMK) trend test (Mann, 1945; Kendall, 1955; Hamed and Rao, 1998) was employed to capture the trends of precipitation and air temperature at monthly and annual scale in the WRB. The initial Mann-Kendall (MK) test recommended by the World Meteorological Organization (Mitchell et al., 1966) is a non-parametric approach. However,
Table 1. Information on meteorological stations analysed in this study.

\begin{tabular}{lcccc}
\hline $\begin{array}{l}\text { Station } \\
\text { name }\end{array}$ & $\begin{array}{c}\text { Station } \\
\text { number }\end{array}$ & $\begin{array}{c}\text { Altitude } \\
(\mathrm{m})\end{array}$ & $\begin{array}{c}\text { Longitude } \\
(\mathrm{E})\end{array}$ & $\begin{array}{c}\text { Latitude } \\
(\mathrm{N})\end{array}$ \\
\hline Lintao & 1 & 1893.8 & 103.85 & 35.35 \\
Minxian & 2 & 2315 & 104.02 & 34.43 \\
Huajialin & 3 & 2450.6 & 105 & 35.38 \\
Xiji & 4 & 1916.5 & 105.72 & 35.97 \\
Tianshui & 5 & 1141.7 & 105.75 & 34.58 \\
Guyuan & 6 & 1753 & 106.27 & 36 \\
Pingliang & 7 & 1346.6 & 106.67 & 35.55 \\
Baoji & 8 & 612.4 & 107.13 & 34.35 \\
Huanxian & 9 & 1255.6 & 107.3 & 36.58 \\
Xifengzhen & 10 & 1421 & 107.63 & 35.73 \\
Changwu & 11 & 1206.5 & 107.8 & 35.2 \\
Foping & 12 & 827.2 & 107.98 & 33.52 \\
Wuqi & 13 & 1331.4 & 108.17 & 36.92 \\
Wugong & 14 & 447.8 & 108.22 & 34.25 \\
Xi'an & 15 & 397.5 & 108.93 & 34.3 \\
Tongchuan & 16 & 978.9 & 109.07 & 35.08 \\
Zhen'an & 17 & 693.7 & 109.15 & 33.43 \\
Yan'an & 18 & 958.5 & 109.5 & 36.6 \\
Luochuan & 19 & 1159.8 & 109.5 & 35.82 \\
Shangzhou & 20 & 742.2 & 109.97 & 33.87 \\
Huashan & 21 & 2064.9 & 110.08 & 34.48 \\
\hline
\end{tabular}

its test results were affected by the persistence of the hydro-meteorological series. Therefore, Hamed and Rao (1998) improved it by taking into account the lag- $i$ autocorrelation to remove the persistence. Hamed and Rao (1998) 
and Daufresne et al. (2009) stated that the MMK test is robust for computing trends of hydro-meteorological series. Thus, the MMK test was used in this study.

For a time series of $n$ observations $X=x_{1}, x_{2}, \ldots, x_{n}$, the MK trend statistic $S$ is computed as follows:

$$
S=\sum_{i<j} \operatorname{sgn}\left(x_{j}-x_{i}\right)
$$

where

$$
\operatorname{sgn}\left(x_{j}-x_{i}\right)=\left\{\begin{array}{cc}
1 & x_{j}>x_{i} \\
0 & x_{j}=x_{i} \\
-1 & x_{j}<x_{i}
\end{array}\right.
$$

The variance of $S$ is proposed by (Kendall, 1955):

$$
\operatorname{Var}(S)=\frac{n(n-1)(2 n+5)}{18}
$$

Then, the standardized test statistic $Z=\frac{S}{\sqrt{\operatorname{Var}(S)}}$ with the standard normal variable under the desired confidence level is calculated to test the significance of the time series trend. Hamed and Rao (1998) indicated that the significant temporal autocorrelations of a time series would disturb the evaluation of the variance of $S$. To remove the influence of the persistence, Hamed and Rao (1998) suggested extracting a nonparametric trend estimator from the original time series to estimate the autocorrelation coefficients of the new time series. Autocorrelation coefficients $\left[\rho_{s}(i)\right.$ at lag $\left.(i)\right]$, which are significantly different from zero under $95 \%$ confidence level, are then utilized to estimate the modified variance of $S$ and $V^{*}(S)$ as follows:

$$
V^{*}(S)=\operatorname{Var}(S) \text { Cor }
$$

where Cor is a correction due to autocorrelation in the time series, which is calculated as follows:

$$
\begin{aligned}
\text { Cor }=1 & +\frac{2}{n(n-1)(n-2)} \\
& \sum_{i=1}^{n-1}(n-1)(n-i-1)(n-i-2) \rho_{S}(i)
\end{aligned}
$$

\subsection{The $K$-means cluster analysis}

The 21 meteorological stations involved in this study were clustered by the $K$-means cluster analysis method based on elevation, latitude, longitude, average annual air temperature and precipitation (Forgy, 1965; Spath, 1985). Note that the number of clusters should be predetermined for the $K$-means cluster analysis and each station can only be classified into one cluster. The number of clusters is determined by the Dunn index ranging from 2 to 20 (Dunn, 1974). The Dunn index acquires the maximum for the allocation that optimizes the combination of inter-cluster distances and inter-station distances to a cluster. The distance of elevation, latitude, longitude, average annual air temperature and precipitation in each station to each cluster centre are calculated. Then, the belongingness is assigned to the closest cluster (Adam and Michael, 2009). A $v$-fold cross validation is applied to estimate how robust the cluster allocation is. Procedures of the v-fold cross validation are presented as follows:

1. For each allocation (2-20 clusters), the $K$-means cluster analysis is implemented using all input data. This analysis produces a reference membership for each sort of data.

2. The collection of all input data values are then randomly divided into ten equal-size folds (Dunn, 1974).

3. The $K$-means cluster analysis is repeated using the nine folds.

4. Cluster membership for the input data extracted in a fold is computed based on new clusters to generate a test membership for each input data. This step is repeated ten times, guaranteeing a different fold each time. Then, all the input data have the test and reference membership.

5. Lastly, the misclassification rate is computed, which denotes the total number of the input data with a great difference between the reference and test membership.

3.3. Concentration ratio of annual precipitation distribution

In order to investigate the response of precipitation to the changing temperature in every sub-region from a precipitation structure perspective, the concentration ratio of annual precipitation distribution is adopted in this study.

Suppose a precipitation series $Q(t, \tau), t=1,2, \ldots, n$ and $\tau=1,2, \ldots, 12$, where $t$ and $\tau$ denote the number of year and month, respectively, and the concentration ratio can be calculated as follows:

$$
\begin{gathered}
C_{d}(t)=Q_{x y}(t) / \sum_{\tau=1}^{12} Q(t, \tau) \\
Q_{x y}(t)=\sqrt{Q_{x}^{2}(t)+Q_{y}^{2}(t)} \\
Q_{x}(t)=\sum_{\tau=1}^{12} Q(t, \tau) \cos \theta(t), \quad Q_{y}(t)=\sum_{\tau=1}^{12} Q(t, \tau) \sin \theta(t)
\end{gathered}
$$

where $C_{\mathrm{d}}(t)$ denotes the concentration ratio of annual distribution in the $t$ th year, $Q(t, \tau)$ stands for the precipitation of the $\tau$ th month in the $t$ th year, $Q_{x}(t)$ and $Q_{y}(t)$ represent the component of vector in the direction of $x$ and $y$, respectively, $Q_{x y}(t)$ is the modulus of the combined vector, and $\theta(t)=2 \pi \tau / 12$.

\subsection{Marginal distribution}

As the annual air temperature and precipitation data used in the study are continuous, gamma distribution, exponential distribution and lognormal distribution are used in this study, which are frequently applied to fit the distribution of hydrological and meteorological series (Mathier et al., 1992; Shiau, 2006). Parameters of the three distributions were estimated by the maximum likelihood estimation (MLE). The goodness-of-fit of each distribution was assessed using the Kolmogorov-Smirnov $(\mathrm{K}-\mathrm{S})$ approach to select the appropriate distribution for each individual annual hydro-meteorological series (Wilks, 1999). 


\subsection{Copulas}

As the Archimedean copula family can be easily constructed, the Clayton, Frank and Gumbel copulas were used to analyse the joint probability distribution of hydro-meteorological series. The important step of determining a copula is to obtain its generating function from bivariate observations. The specific procedures to obtain the generating function and the resulting copula can be referred to Genest and Rivest (1993). As the procedures are very common, they are not introduced in this study.

The Bayesian copula selection method proposed by Huard et al. (2006) was adopted to estimate their fitting effects and select the most appropriate copula function. As the existing methods have a lot of difficulties in choosing the appropriate copula family and none is completely satisfying, the Bayesian copula selection method, which is a simple and reliable method for selecting the most appropriate copula, is utilized in this study. The specific procedures can be referred to Huard et al. (2006), and the related program codes can be free downloaded in this website: http://code.google.com/p/copula/.

3.6. Identify inflection point of the relationship between precipitation and temperature

Consider a series $\left(x_{1}, y_{1}\right), \ldots,\left(x_{n}, y_{n}\right)$ in which if there is only one inflection point of the Archimedean copula function, then the null hypothesis and alternative hypothesis are expressed as follows:

$$
\begin{aligned}
& H_{0}: \lambda_{1}=\lambda_{2}=\cdots=\lambda_{n} ; \\
& H_{1}: \lambda_{1}=\cdots=\lambda_{k *} \neq \lambda_{k *+1}=\cdots=\lambda_{n}
\end{aligned}
$$

If the null hypothesis is rejected, then $K^{*}$ will be the corresponding time of the inflection point. When $k^{*}=k$ is known, the logarithmic likelihood ratio statistics of copula based on the MLE method can be constructed as follows:

$$
\begin{gathered}
-2 \log \wedge_{k}=2\left[\sum_{i=1}^{k} \log C_{12}\left(\lambda_{k} ; F\left(x_{i}\right), G\left(y_{i}\right)\right)\right. \\
+\sum_{i=k+1}^{n} \log C_{12}\left(\lambda_{k^{*}} ; F\left(x_{i}\right), G\left(y_{i}\right)\right) \\
\left.\quad-\sum_{i=1}^{n} \log C_{12}\left(\lambda_{n} ; F\left(x_{i}\right), G\left(y_{i}\right)\right)\right]
\end{gathered}
$$

where $\lambda_{k}, \lambda_{k^{*}}$ and $\lambda_{n}$ are the MLE of the parameter $\lambda$ of the related data. In view of imitative effects of marginal and joint distribution, $k$ is confined between 7 and $n-6$.

If $K^{*}$ is not known, then

$$
Z_{n}=\max _{7 \leq k \leq n-6}\left(-2 \log \wedge_{k}\right)
$$

When the statistics $Z_{n}$ is large enough to reject the null hypothesis, there is an inflection point of the Archimedean copula. The statistics $Z_{n}$ follows Chi-square distribution. The threshold of statistics $Z_{n}$ is approximately 9 (Costa, 2004). The time corresponding to the inflection point can be estimated as follows:

$$
k^{*}=\arg \max _{7 \leq k \leq n-6}\left(-2 \log \wedge_{k}\right)
$$

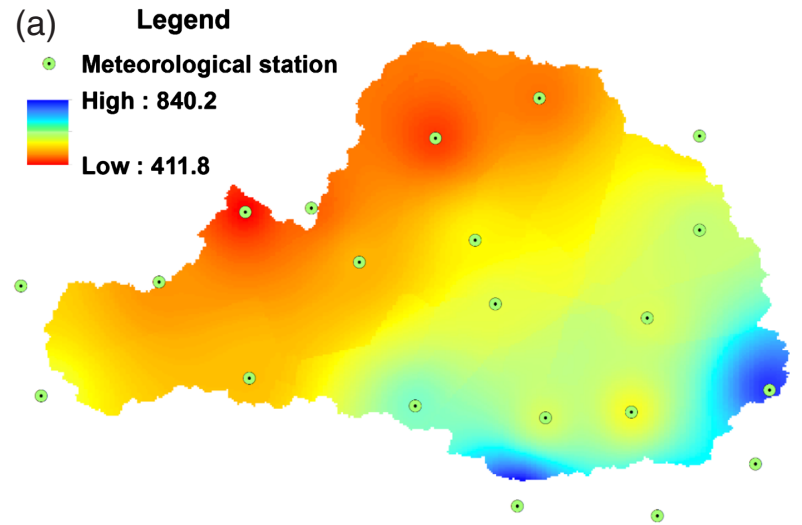

(b)

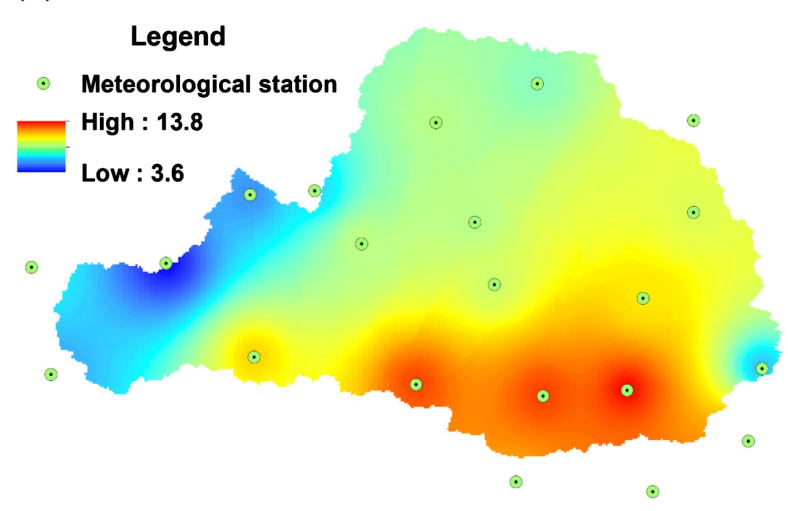

Figure 2. The spatial distribution of annual average precipitation (a) and temperature (b) in the WRB.

\section{Results and discussion}

4.1. The spatial distribution of annual average precipitation and air temperature in the WRB

The annual average precipitation and air temperature at all the stations were computed based on daily precipitation and average air temperature. They were interpolated by the inverse distance weighted method using ArcGIS software, and their spatial distributions are exhibited in Figure 2.

It can be obviously seen that the annual average precipitation decreases from the southeast to the northwest of the WRB, which is opposite to its corresponding altitude to a great extent. The precipitation in the WRB is primarily controlled by the southeast monsoon, which mainly goes forward from southeast to northwest (Huang et al., 2014b). When it is in the process of moving towards northwest basin, the moisture reduces and precipitation decreases. It should be pointed out that the average annual precipitation of Foping and Huashan meteorological stations is distinctly larger than others primarily because of their locations situated in the south of the Qinling Mountain and in its windward slope, resulting in the great amount of precipitation. It should be noted that the less precipitation areas happen to be the fragile ecological regions. Therefore, local climate condition could have an adverse influence on the ecology and environment of these regions.

Similarly, the annual air temperature in the WRB decreases from southeast to northwest. In general, it is 


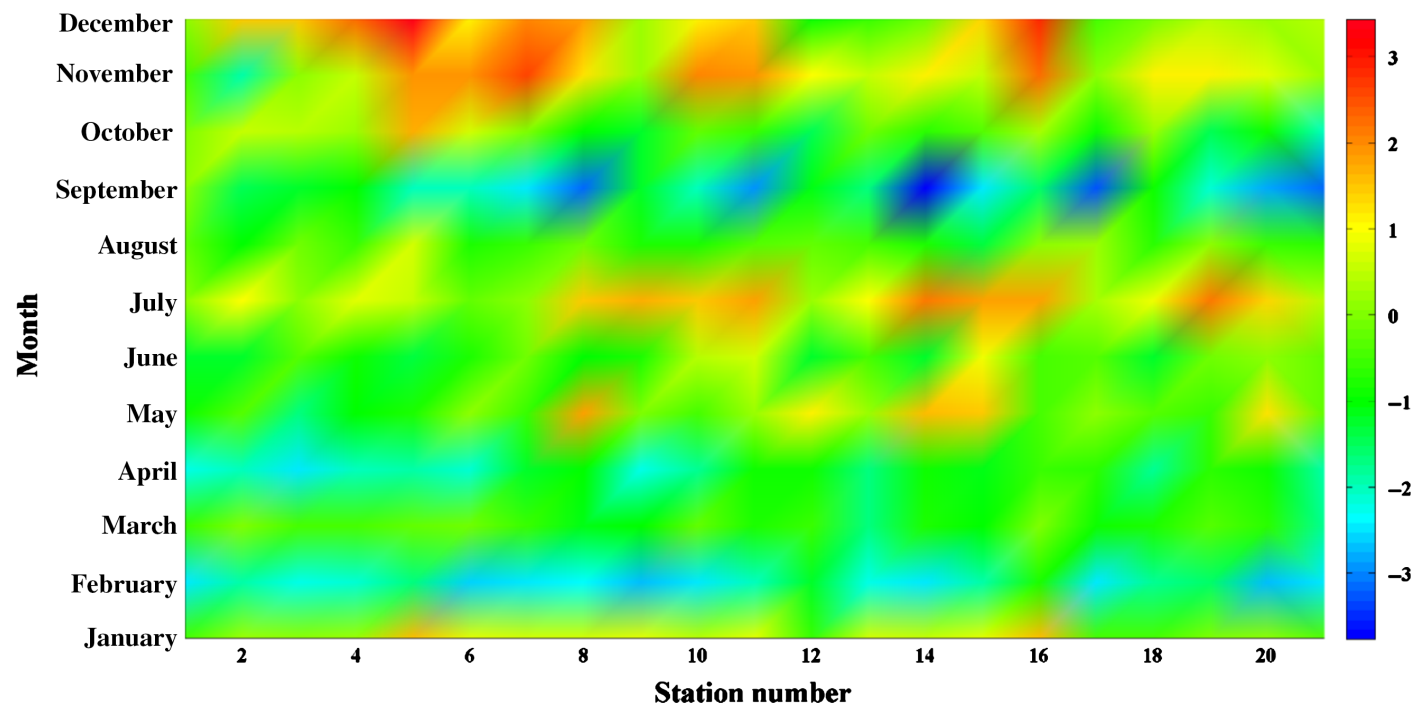

Figure 3. The monthly precipitation trend in each month at each station in the WRB.

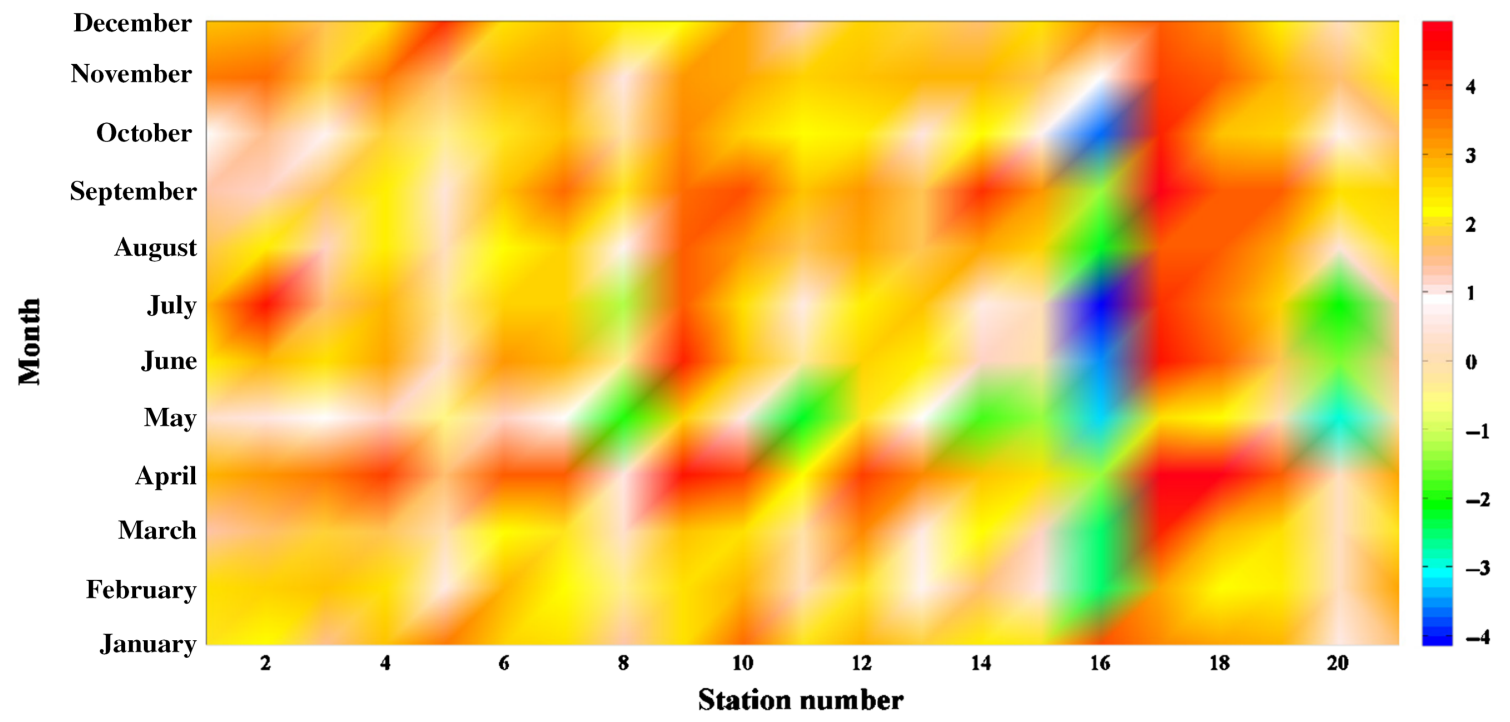

Figure 4. The monthly average air temperature trend in each month at each station in the WRB.

also contrary to the corresponding altitude. However, it is worth mentioning that only a small apart of the eastern basin has a relatively low temperature because of the location of Huashan station at a high altitude of $2160 \mathrm{~m}$. Additionally, it can be easily observed from Figure 2(b) that the highest temperature is primarily concentrated in the Guanzhong Plain.

\subsection{The trends of precipitation and average air temperature}

In order to investigate the trends of precipitation and average air temperature at monthly scale, the MMK test method was used in this study, and the trends of monthly precipitation and average air temperature are shown in Figures 3 and 4, respectively.

With regard to the MMK test method, when the absolute value of MMK is larger than 1.96, the trend is significant at the $95 \%$ confidence level. The positive value denotes an upward trend and vice versa. The meteorological stations were arranged according to their magnitudes of longitude, which were ranked from west to east. Hence, the trend of precipitation and air temperature in each month at all stations in Figures 3 and 4 can reflect the spatio-temporal changing characteristics of precipitation and air temperature in the WRB.

It can be obviously seen from Figure 3 that the trends of monthly precipitation at all stations in the WRB are primarily downwards, and the precipitation in the whole basin from January to April and from August to September has a decreasing trend, while a significantly decreasing tendency is found for the August and September in the middle and east of the basin. Conversely, the precipitation in July, November and December has an upward tendency. It can be easily observed from Figure 4 that the average air temperature in almost all months in the WRB has an increasing trend, except for that in May in the middle and 

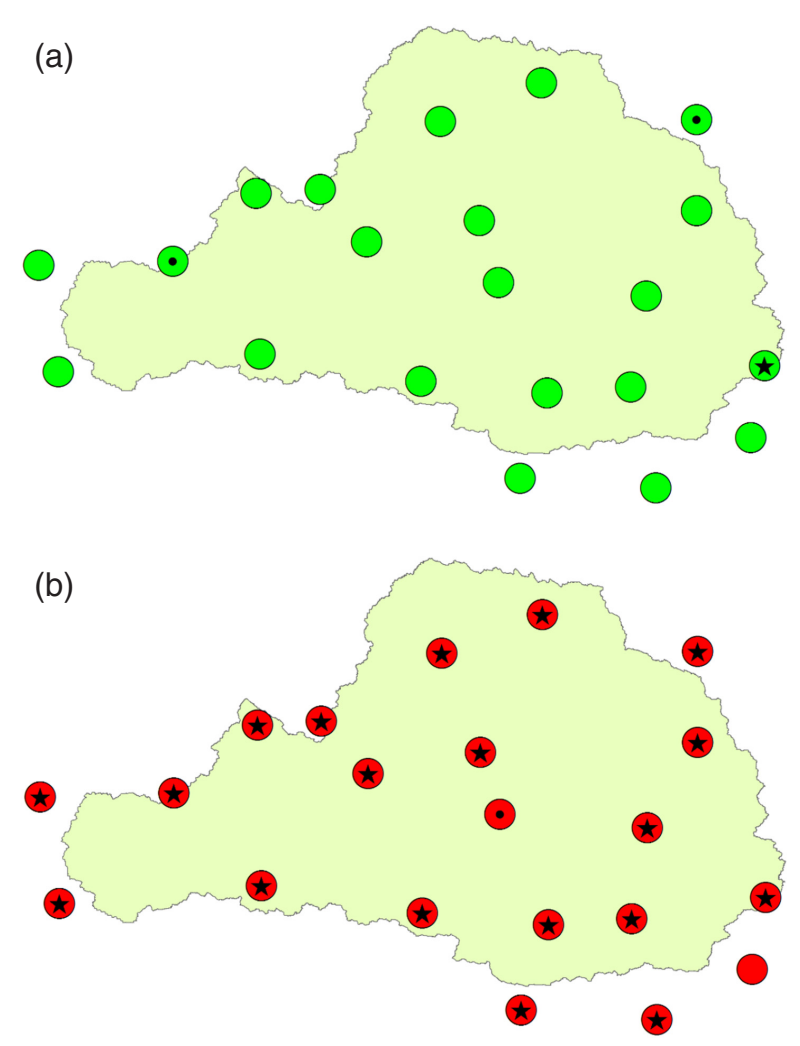

Figure 5. Spatial distribution of annual precipitation (a) and temperature (b) trends in the WRB. Red and green solid circles denote upward and downward trends, respectively, circles with a black dot and five-pointed star stand for significant trends at the 95 and $99 \%$ confidence level, respectively.

east part of the basin. Generally, the WRB is characterized by decreasing precipitation and increasing average air temperature at monthly scale.

Furthermore, the MMK test method was applied to analyse the spatio-temporal changing characteristics of annual precipitation and average air temperature in the WRB, and the results are shown in Figure 5. Obviously, the annual precipitation in all the stations shows a decreasing trend, and most of the stations exhibit a non-significant trend, only that at Huajialin and Yan' an stations have a significant trend at the 95\% confidence level and that at Huashan station shows a significant trend at the $99 \%$ confidence level, implying that the annual precipitation in the whole WRB has a non-significantly decreasing trend, which is consistent with the investigation made by Zhang et al. (2008). Conversely, the annual average air temperature in all the stations shows an increasing trend, and most of the stations exhibit a significant trend at the $99 \%$ confidence level, only that at Shangxian station has a non-significant tendency and that at Changwu station shows a significant trend at the $95 \%$ confidence level, implying that the whole basin is characterized by a strikingly increasing temperature.

\subsection{Homogeneous sub-regions}

The WRB is a large region with a total area of $1.35 \times 10^{5} \mathrm{~km}^{2}$, being characterized by various climate types with various precipitation and temperature characteristics, and different areas have different hydrologic response to the global warming. Thus, in order to accurately investigate the impacts of the increasing temperature on different parts of the basin, it is necessary to divide all meteorological stations into several homogeneous sub-regions. By this, the variations of precipitation and temperature at the stations in a sub-region are statistically similar. In this study, the $K$-means cluster analysis method was employed to divide all stations into several sub-regions based on elevation, latitude, longitude, mean daily max air temperature, average daily min air temperature and mean annual precipitation. According to the procedures outlined in Section 3.2, the results of the $K$-means cluster analysis indicate that the number of clusters with the maximum Dunn index is 3 . The division of sub-regions is exhibited in Figure 1.

4.4. The changes in the concentration ratio of precipitation annual distribution in the sub-regions

In order to comprehensively and systematically analyse the response of precipitation in the sub-regions to the increasing temperature, the changes in magnitude and structure of precipitation should be investigated (Tu et al., 2013). As its change in magnitude has been analysed in Section 4.2., the variations of precipitation structure in the three sub-regions are analysed in this section. The concentration ratio of annual precipitation distribution was used to investigate the change in precipitation structure in this study. According to Equations (6)-(8) outlined in Section 3.3., the concentration ratios of annual precipitation distribution in the three sub-regions are exhibited in Figure 6.

It can be obviously seen from Figure 6 that all the concentration ratios of annual precipitation distribution in the three sub-regions have a non-significant trend. Specifically, a slightly downward trend was found in Zone I, while that in Zones II and III have non-significant upward trends, implying that the increasing temperature has less effect on precipitation structure than precipitation value in the WRB.

\subsection{The selection of the appropriate marginal distribution}

In order to obtain an appropriate marginal distribution, Gamma distribution, exponential distribution and lognormal distribution were used to fit the annual precipitation and air temperature series. Through the $\mathrm{K}-\mathrm{S}$ method, the goodness-of-fit values of the three probability distributions can be computed, and the results are shown in Table 2.

It can be obviously observed from Table 2 that all the $H$ values are 0 except for that of exponential distribution where $H$ values are 1 at the three sub-regions, indicating that exponential distribution is unsuitable to fit the distribution of precipitation and temperature series in the study. Although both Gamma distribution and lognormal distribution have passed the $\mathrm{K}-\mathrm{S}$ test, in general, the $p$ values of Gamma distribution are larger than the corresponding $p$ values of lognormal distribution. Therefore, Gamma distribution is selected as the appropriate marginal distribution in this study. 


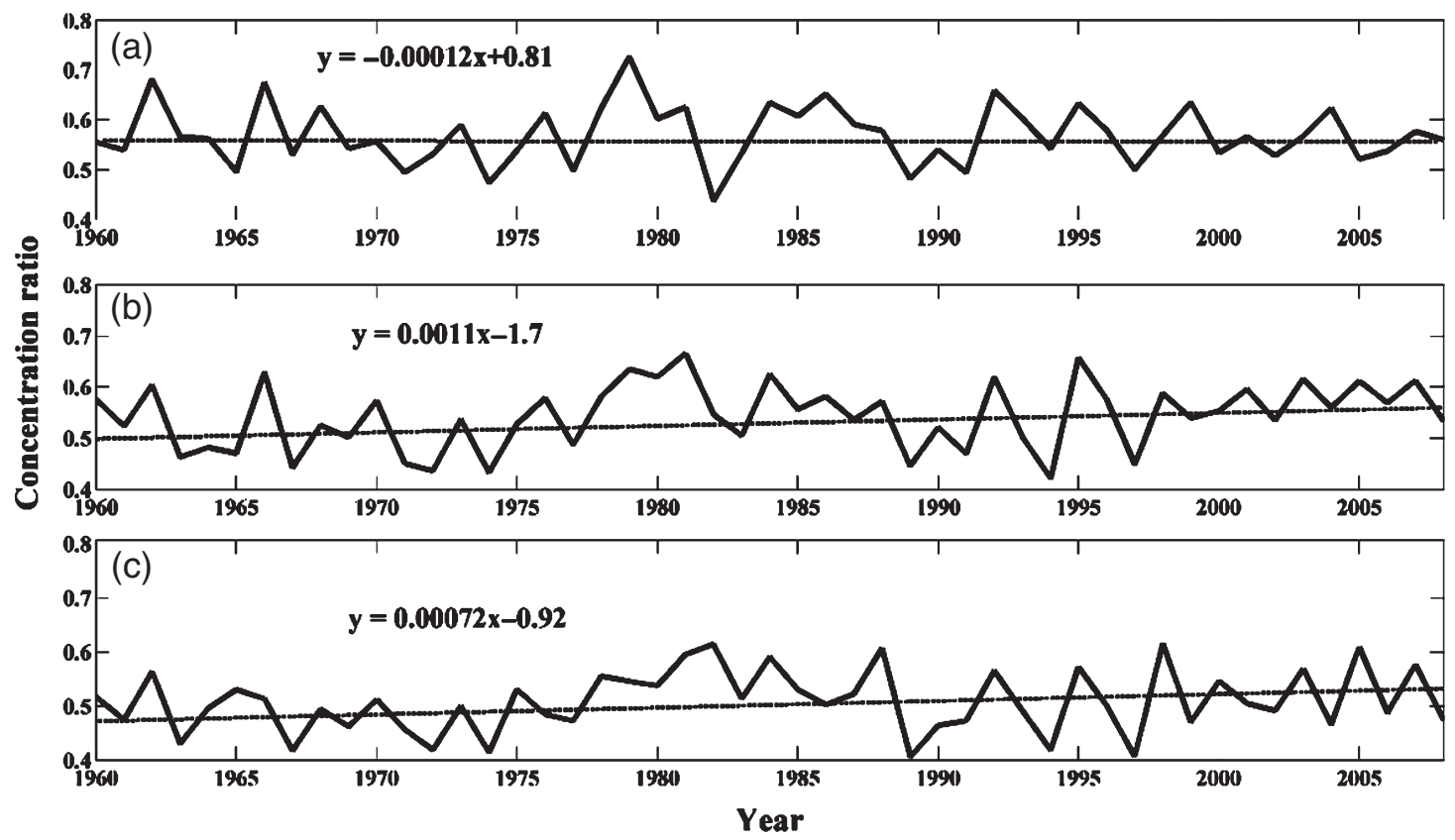

Figure 6. The concentration ratio series of annual precipitation distribution in the three sub-regions. (a), (b) and (c) denote Zones I, II and III, respectively.

Table 2. The goodness-of-fit values of the three probability distributions.

\begin{tabular}{|c|c|c|c|c|c|c|c|}
\hline \multirow[t]{2}{*}{ Sub-regions } & \multirow[t]{2}{*}{ Series } & \multicolumn{2}{|c|}{ Gamma distribution } & \multicolumn{2}{|c|}{ Exponential distribution } & \multicolumn{2}{|c|}{ Lognormal distribution } \\
\hline & & $H$ & $P$ & $H$ & $P$ & $H$ & $P$ \\
\hline \multirow[t]{2}{*}{ Zone I } & $P$ & 0 & 0.71 & 1 & 0 & 0 & 0.67 \\
\hline & $T$ & 0 & 0.55 & 1 & 0 & 0 & 0.48 \\
\hline \multirow[t]{2}{*}{ Zone II } & $P$ & 0 & 0.96 & 1 & 0 & 0 & 0.95 \\
\hline & $T$ & 0 & 0.79 & 1 & 0 & 0 & 0.75 \\
\hline \multirow[t]{2}{*}{ Zone III } & $P$ & 0 & 0.81 & 1 & 0 & 0 & 0.69 \\
\hline & $T$ & 0 & 0.64 & 1 & 0 & 0 & 0.57 \\
\hline
\end{tabular}

$P$ and $T$ represent precipitation and temperature, respectively; $H$ denotes the hypothesis test result, returned as a logical value, if $H=0$, indicating that a failure to reject the null hypothesis at 0.05 significance, if $H=1$, indicating the rejecting of the null hypothesis at 0.05 significance; $P$ represents $p$ value of the test, returned as a scalar value in the range $(0,1)$, small values of $P$ cast doubt on the validity of the null hypothesis.

Table 3. The weights of Clayton, Frank and Gumbel copulas in fitting joint distribution of precipitation and temperature.

\begin{tabular}{lccc}
\hline Sub-regions & Clayton & Frank & Gumbel \\
\hline Zone I & 0.32 & 0.41 & 0.59 \\
Zone II & 0.39 & 0.51 & 0.55 \\
Zone III & 0.32 & 0.39 & 0.49 \\
\hline
\end{tabular}

\subsection{The selection of the appropriate copula}

Once the marginal distribution is determined, the Bayesian copula selection method was employed to select the most appropriate copula from Clayton, Frank and Gumbel copulas which were used to fit the joint distribution of precipitation and temperature series in the study. The weights of the three copulas are displayed in Table 3 . It can be obviously seen from Table 3 that the weights of Gumbel copula in fitting the joint distribution of precipitation and temperature series are highest, indicating that Gumbel copula is the best one to fit their joint distribution in the WRB.
4.7. The identification of inflection point between precipitation and temperature in the WRB

The copulas-based method was used to identify the possible inflection points between precipitation and temperature in the WRB. Based on the procedures outlined in Section 3.6., the statistics of the copulas-based method in the three sub-regions are computed and illustrated in Figure 7.

It can be seen from Figure 7 that the statistic in Zone I in 1966-2001 ranges from 0 to 4.9 and its largest value of 4.9 occurs in 1994, whose value is less than the threshold (approximately 9) of rejecting the null hypothesis. Therefore, there is no inflection point of the relationship between precipitation and temperature in Zone I. However, the statistics in Zones II and III are confined to $-1 \times 10^{-5}$ to $3 \times 10^{-5}$ and $0-4 \times 10^{-5}$, respectively, which are almost zero. Hence, the relationships between precipitation and temperature in Zones II and III almost have no changes. Although there is no inflection point between precipitation and temperature in Zone I, its relationship has slightly changed because of its relatively high statistic. Therefore, 

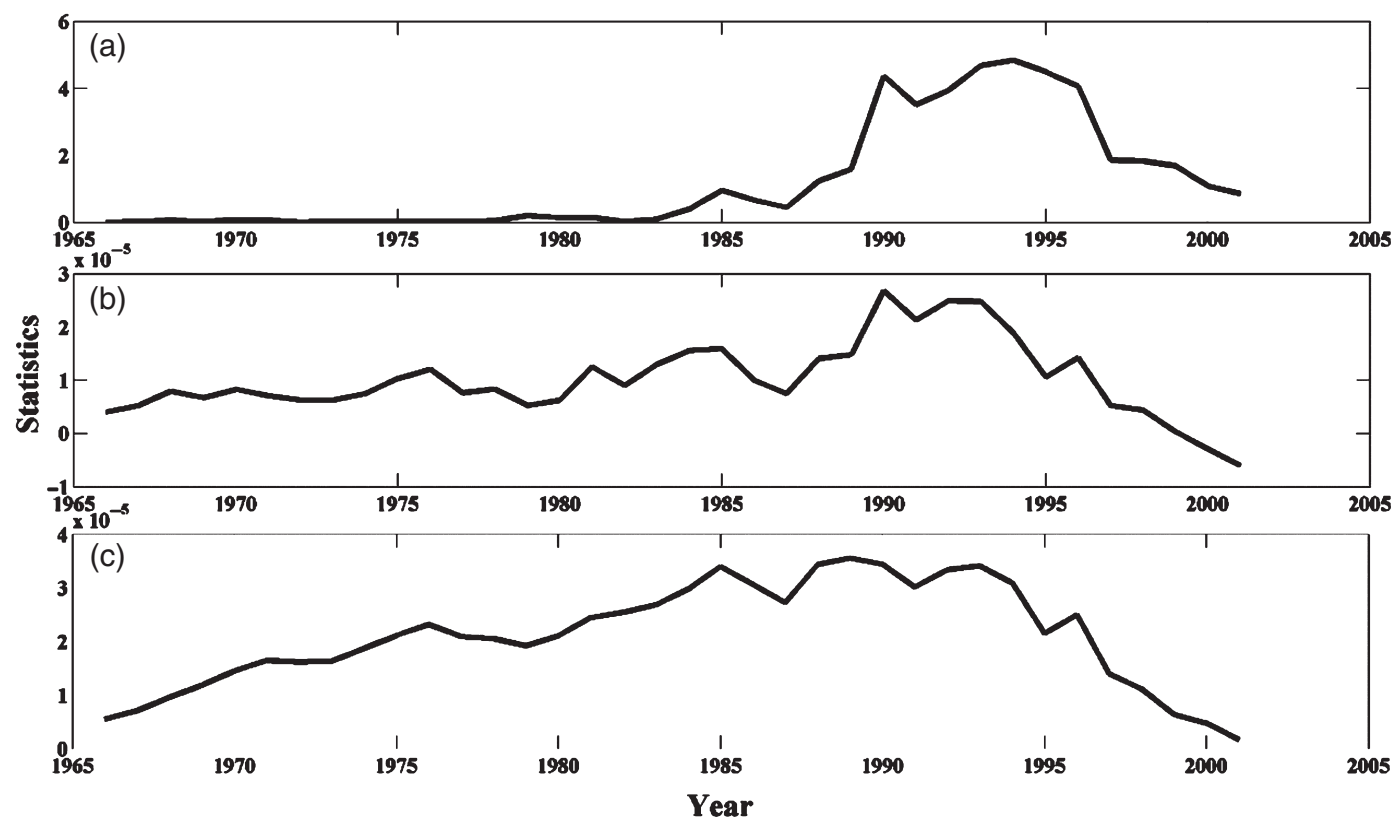

Figure 7. The statistics of copulas-based method in the three sub-regions. (a), (b) and (c) denote Zones I, II and III, respectively.

the relationships between precipitation and temperature in the middle and east part of the basin have not strikingly changed under the background of global warming, while that in the west of basin has slightly changed. Generally, the relationship between precipitation and temperature in the whole WRB has no significant inflection point. This implies that the relationship between precipitation and temperature is relatively stable under the backdrop of the global climate change.

\section{Conclusions}

With the purpose of further understanding the hydrologic response to the background of climate change based on the relationship between precipitation and temperature in the WRB, which is a typical arid and semi-arid region in China, an investigation has been made to investigate the spatio-temporal changes in precipitation, temperature and their possibly changing relationship. The MMK trend test was applied to capture the trends of precipitation and average air temperature at monthly and annual scale, and the $K$-means cluster analysis method was employed to divide all the meteorological stations into three homogeneous sub-regions. Besides, the concentration ratio of annual precipitation distribution was used to analyse the response of precipitation structure to the increasing temperature in the sub-regions. Furthermore, a copulas-based method was introduced in this study to identify the possible inflection points of the relationship between precipitation and temperature. The main conclusions obtained in this study are presented as follows:

1. The average annual precipitation and temperature in the WRB have a striking regional distribution characteristic. Both precipitation and temperature gradually decrease from southeast to northwest. Roughly, the average annual precipitation and temperature show a negative correlation with the corresponding elevation to a great extent.

2. From the perspective of monthly scale, the trends of monthly precipitation at all stations in the WRB are primarily downwards, and the precipitation in the whole basin from January to April and from August to September has a decreasing trend, while that of August and September has a significantly decreasing tendency in the middle and east of the basin. Conversely, the precipitation in July, November and December has an upward tendency. Regarding the average air temperature, the WRB in almost all months has an increasing trend, except for that in May in the middle and east part of the basin. From the perspective of annual scale, the annual precipitation in all the stations has a decreasing trend, and most of the stations exhibits a non-significant trend, whereas the annual temperature in all the stations have an increasing trend, and most of the stations exhibit a significant trend at the 99\% confidence level.

3. All the meteorological stations were divided into three sub-regions based on the $K$-means cluster analysis method, and all the concentration ratios of annual precipitation distribution in the three sub-regions show no obvious trend, implying that the increasing temperature has less effect on precipitation structure than precipitation magnitude in the WRB.

4. The relationships between precipitation and temperature in the middle and east part of the basin have no changes under the background of global warming, while the west of basin has a slight change. Generally, the relationship between precipitation and temperature in the whole WRB is relatively stable. 
In conclusion, this research provides a new idea and quantitative measure for the identification of inflection points of the relationship between precipitation and temperature, which also can be an effective reference for the detection of inflection points of the relationship between other hydrological and meteorological multivariable.

It would be interesting to explore whether the findings of this study remain in the future with anthropogenic climate caused by the continued greenhouse-gas emissions, which could provide guidance for the adaptation and mitigation strategies, and water resources management in the future. With the newly available CMIP5 (Coupled Model Intercomparison Project Phase 5) climate model outputs, future studies will be performed by examining the relationship between precipitation and temperature through the copulas-based method as introduced in the present study.

\section{Acknowledgements}

This research was supported by National Major Fundamental Research Program (2011CB403306-2), the National Natural Fund Major Research Plan (51190093), the Natural Science Foundation of China (51179148, 51179149, and 51379014), and the China Scholarship Council.

\section{References}

Adam R, Michael HS. 2009. Crouch gait patterns defined using k-means cluster analysis are related to underlying clinical pathology. Gait Posture 30: $155-160$.

Alexander LV, Zhang X, Peterson TC, Caesar J, Gleason B. 2006. Global observed changes in daily climate extremes of temperature and precipitation. J. Geophys. Res. 111: D05109.

Allan RP, Soden BJ. 2008. Atmospheric warming and the amplification of precipitation extremes. Science 321: 1481-1484.

Allen MR, Ingram WJ. 2002. Constraints on future changes in climate and the hydrologic cycle. Nature 419: 224-232.

Arnell NW. 1999. Climate change and global water resources. Glob. Environ. Change 9: S31-S49.

Boccolari M, Malmusi S. 2013. Changes in temperature and precipitation extremes observed in Modena, Italy. Atmos. Res. 122: 16-31.

Costa DAD. 2004. Copula Inference for Finance and Insurance. Doctoral thesis, ETH, Zurich, Switzerland.

Daufresne M, Lengfellner K, Sommer U. 2009. Global warming benefits the small in aquatic ecosystems. Proc. Natl. Acad. Sci. U.S.A. 106(31): $12788-12793$.

Du HB, Wu ZF, Jin YH, Zong SW, Meng XJ. 2013. Quantitative relationships between precipitation and temperature over Northeast China, 1961-2010. Theor. Appl. Climatol. 113(3-4): 659-670.

Dunn JC. 1974. A fuzzy relative of the ISODATA process and its use in detecting compact well separated clusters. J. Cybern. 3(3): 32-57.

Easterling DR, Horton B, Peterson TC, Karl TR, Parker DE, Salinger MJ, Razuvayev V, Plummer N, Jamason P, Folland CK. 1997. Maximum and minimum temperature trends for the globe. Science 277(5324): $364-367$.

Forgy EW. 1965. Cluster analyses of multivariate data: efficiency versus interpretability of classifications. Biometrics 21: 768-769.

Genest C, Rivest L. 1993. Statistical inference procedures for bivariate Archimedean copulas. Journal of the American statistical association 88(423): 1034-1043.

Hamed KH, Rao AR. 1998. A modified Mann-Kendall trend test for autocorrelated data. J. Hydrol. 204: 182-196.

Huang SH, Chang JX, Huang Q, Chen YT. 2014a. Spatio-temporal changes and frequency analysis of drought in the Wei River Basin, China. Water Resour. Manage. 28(10): 3095-3110.

Huang SZ, Chang JX, Huang Q, Chen YT. 2014b. Spatial-temporal change in precipitation patterns based on the cloud model across Wei River Basin, China. Theor. Appl. Climatol. 120(1-2): 391-401.
Huard D, Guillaume É, Anne-Catherine F. 2006. Bayesian copula selection. Comput. Stat. Data Anal. 51: 809-822.

Intergovernmental Panel on Climate Change (IPCC). 2007. Climate Change 2007: The Physical Science Basis. Contribution of Working Group I to the Fourth Assessment Report of the Intergovernmental Panel on Climate Change. Cambridge University Press: Cambridge, UK, 1-996.

Jordan YC, Ghulam A, Chu ML. 2014. Assessing the impacts of future urban development patterns and climate changes on total suspended sediment loading in surface waters using geoinformatics. J. Environ. Inform. 24(2): 65-79.

Józsa J, Kiely G, Borthwick AGL. 2014. Sediment flux and its environmental implications. J. Environ. Inform. 24(2): 111-120.

Kao SC, Govindaraju RS. 2010. A copula-based joint deficit index for droughts. J. Hydrol. 380: 121-134.

Kendall MG. 1955. Rank Correlation Methods. Griffin: London.

Lima MP, Santo FE, Ramosd AM, Limaa JL. 2013. Recent changes in daily precipitation and surface air temperature extremes in mainland Portugal, in the period 1941-2007. Atmos. Res. 127: 195-209.

Ling J, Wu ML, Chen YF, Zhang YY, Dong JD. 2014. Identification of spatial and temporal patterns of coastal waters in Sanya Bay, South China Sea by chemometrics. J. Environ. Inform. 23(1): 37-43.

Ma ZZ, Wang ZJ, Xia T, Gippel CJ, Speed R. 2014. Hydrograph-based hydrologic alteration assessment and its application to the Yellow River. J. Environ. Inform. 23(1): 1-13.

Madanian MA, Soffianian A, Hajian A. 2014. Change detection through four techniques using multi-temporal Landsat thematic mapper data: a case study on Falavarjan Area, Isfahan, Iran. J. Environ. Inform. 23(2): 58-66.

Mann HB. 1945. Nonparametric tests against trend. Econometrica 13: 245-259.

Mann ME, Gille E, Overpeck J, Gross W, Bradley RS, Keimig Frank T, Hughes MK. 2000. Global temperature patterns in past centuries: an interactive presentation. Earth Interact. 4: 1-29.

Mathier L, Perreault L, Bobée B, Ashkar F. 1992. The use of geometric and gamma-related distributions for frequency analysis of water deficit. Stoch. Hydrol. Hydraul. 6(4): 239-254.

Mitchell JM, Dzerdzeevskii B, Flohn H. 1966. Climate change. WHO Technical Note 79, World Meteorological Organization, Geneva, Switzerland, $79 \mathrm{pp}$.

Palynchuk D, Guo Y. 2011. A probabilistic description of rain storms incorporating peak intensities. J. Hydrol. 409: 71-80.

Shiau JT. 2006. Fitting drought duration and severity with two-dimensional Copulas. Water Resour. Manage. 20: 795-815.

Spath H. 1985. Cluster Dissection and Analysis: Theory. Halsted Press: New York, NY.

Trenberth KE. 1999. Conceptual framework for changes of extremes of the hydrological cycle with climate change. Clim. Change 42: $327-339$.

Tu XJ, Chen XH, Zhang Q, Li N. 2013. Streamflow annual distribution and its influencing factors in Dongjiang River, South China. Adv. Water Sci. 4: 493-500 (in Chinese).

Wang XJ, Gebremichael M, Yan J. 2010. Weighted likelihood copula modeling of extreme rainfall events in Connecticut. J. Hydrol. 390: $108-115$

Wang QX, Fan XH, Qin ZD, Wang MB. 2012. Change trends of temperature and precipitation in the Loess Plateau Region of China, 1961-2010. Glob. Planet Change 92-93: 138-147.

Wang BL, Zhang MJ, Wei J, Wang S, Li S, Ma Q, Li X, Pan S. 2013a. Changes in extreme events of temperature and precipitation over Xinjiang, northwest China, during 1960-2009. Quart. Int. 298: $141-151$.

Wang SJ, Jiao ST, Xin H. 2013b. Spatio-temporal characteristics of temperature and precipitation in Sichuan Province, Southwestern China, 1960-2009. Quart. Int. 286: 103-115.

Wilks DS. 1999. Interannual variability and extreme-value characteristics of several stochastic daily precipitation models. Agric. For. Meteorol. 93: $153-169$.

Ye WY, Miao BQ. 2009. Analysis of sub-prime crisis contagion based on change point testing method of Copula. Chin. J. Manage. Sci. 17(3): 1-7 (in Chinese).

Zhang H, Chen Y, Ren G, Yang G. 2008. The characteristics of precipitation variation of Weihe River Basin in Shaanxi Province during recent 50 years. Agric. Res. Arid Areas 26(4): 236-242 (in Chinese).

Ziegler AD, Sheffield J, Maurer EP, Nijssen B, Wood EF, Lettenmaier DP. 2003. Detection of intensification in global- and continental-scale hydrological cycles: temporal scale of evaluation. J. Clim. 16: 536-547. 